\title{
Beta irradiation: new uses for an old treatment: a review
}

JF Kirwan ${ }^{1}$, PH Constable ${ }^{2,3}$, IE Murdoch ${ }^{1,4}$ and PT Khaw $^{2,4}$

beta radiation in the prevention of restenosis following coronary balloon angioplasty or stenting is highly topical. Placement of ${ }^{32} \mathrm{P}$ wires markedly reduced subsequent restenosis rates in a recently reported randomised controlled trial, and extensive investigation continues in this field. ${ }^{1,2}$ In ophthalmology, the role of both external beam radiation and brachytherapy in the management of age-related macular degeneration (ARMD) and the role of beta radiation in trabeculectomy are currently under evaluation. It is therefore appropriate to revisit the role of beta radiation in ophthalmology.

\section{Beta radiation}

Beta radiation is a particulate radiation consisting of high-speed electrons, which are rapidly attenuated by biological tissues $(2 \mathrm{MeV}$ beta particles have a range of only $1 \mathrm{~cm}$ in water). This makes it very useful for superficial radiation treatments where deep tissue penetration is undesirable. Strontium-90 $\left({ }^{90} \mathrm{Sr}\right)$, an unstable fission product of uranium-235 $\left({ }^{235} \mathrm{U}\right)$, has been found to be a clinically useful source of beta radiation as it has a long half-life (28.7 years) and emits only high-energy beta particles as it decays. Ruthenium-106 $\left({ }^{106} \mathrm{Ru}\right)$ primarily emits beta radiation but also emits a small but significant gamma component. ${ }^{3}{ }^{106} \mathrm{Ru}$ has been primarily used in the treatment of choroidal melanoma. ${ }^{4,5}$ Penetration depends on the energy of particles released in the decay process of a particular source. Of emitters used in ophthalmology, the ${ }^{90} \mathrm{Sr}$ source has the most marked attenuation in biological tissues, making it particularly suitable for use in ocular surface treatment. The half thickness of ${ }^{90} \mathrm{Sr}$ is $1.5 \mathrm{~mm}$, that is, the radiation dose rate is attenuated by $50 \%$ after $1.5 \mathrm{~mm}$ penetration through water - the corresponding distance for ${ }^{106} \mathrm{Ru}$ is $2.4 \mathrm{~mm}$. One potential problem with beta radiation is in the generation of secondary $\mathrm{X}$-rays, termed Bremsstrahlung, caused by braking of the highenergy electrons by the material the source is
${ }^{1}$ Department of Epidemiology and International Eye Health Institute of Ophthalmology London, UK

\section{${ }^{2}$ Wound Healing} Research Unit Institute of Ophthalmology London UK

${ }^{3}$ Department of Ophthalmology Royal Berkshire Hospital Reading, UK

${ }^{4}$ Moorfields Eye Hospital City Road

London, UK

Correspondence:

JF Kirwan

Department of Epidemiology and International Eye Health Institute of Ophthalmology 11-43 Bath Street London EC1V9EL UK

Tel: +442076086904

Fax: +44 2072503207

E-mail: jfkirwan@ucl.ac.uk 
embedded in. This may also be relevant if the material is shielded by very proximally placed material with a high atomic number (eg lead). The production of

Bremsstrahlung is usually minimal with the low atomic number atoms found in biological soft tissues.

\section{Method of delivery}

The ${ }^{90} \mathrm{Sr}$ source is commercially available for use in pterygium surgery (Nycomed Amersham, UK)

(Figure 1). The sources remain clinically useful for at least 10 years. Recalculation of the dose rate is required periodically as the activity of the emitter slowly decays.

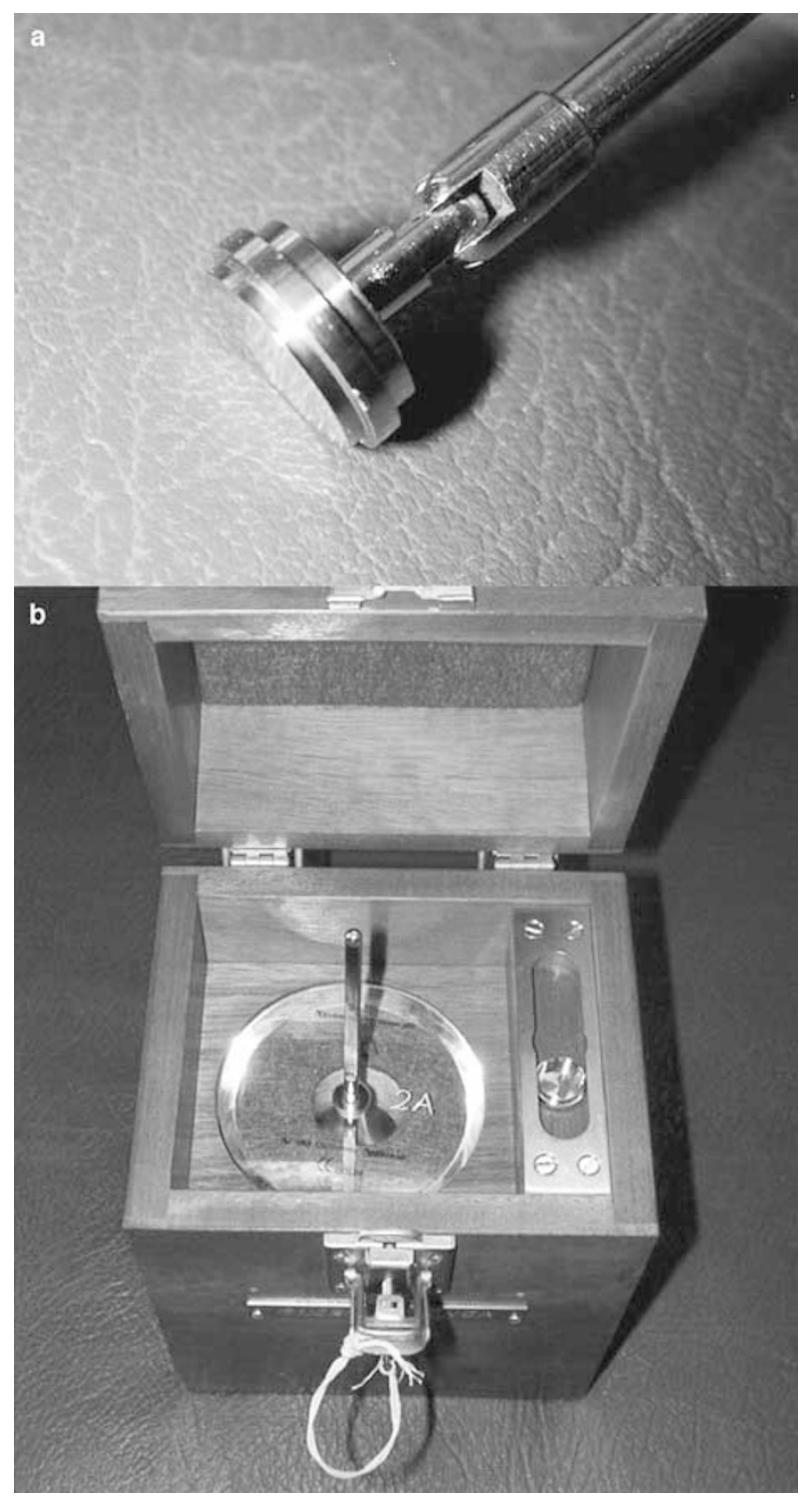

Figure 1 (a) Tip of ${ }^{90} \mathrm{Sr}$ emitter (Nycomed Amersham, UK). (b) Emitter in protective case with lid open to reveal emitter handle and perspex shield.
Typically, this is done every 6 or 12 months. These sources have also been used with trabeculectomy. The dimensions of this source, $11 \mathrm{~mm}$ diameter (round) and $3 \mathrm{~mm}$ thickness, are not ideal for trabeculectomy, as excellent exposure is required for application. However, smaller sources are also available (BEBIG, Berlin). In future, a custom-shaped device may be available. The source we are using is available with a mask to allow delivery to particular areas; however, to ensure reliable dosimetry, we use these without masking. The dose rate depends on the individual characteristics of a particular source and how much ${ }^{90} \mathrm{Sr}$ is in a particular emitter. With a new source, a dose of 1000 cGy (rad) may be administered over approximately $20 \mathrm{~s}$. After some years, the exposure time may be in the order of several minutes.

\section{Cellular effects of beta radiation}

The fundamental biological effect of ionising radiation is the process of ionisation, where the absorption of energy by an atom or molecule results in the ejection of one or more of its orbiting electrons, resulting in unstable and highly reactive compounds. From its earliest clinical use, it has been clear that radiation influences tissue healing. ${ }^{6}$ In 1932, Desjardins noted that a proportion of irradiated cells exhibited either a temporary inhibition of metabolic activity, or a complete and permanent disintegration, and in 1957, Puck et al demonstrated that the growth of normal fibroblasts in vitro could be inhibited by radiation. ${ }^{7,8}$ In the eye, radiation has been shown to inhibit corneal wound healing, with prominent effects on fibroblast proliferation. ${ }^{9}$ Radiation therapy has also been utilised as a means of preventing proliferative vitreoretinopathy (PVR). ${ }^{10,11}$

The conjunctival fibroblast is at the core of the healing response following trauma to the conjunctiva; their proliferation, contraction, collagen production, and eventual quiescence determine the extent of the overall wound healing response. In rabbit models, which show a considerably more aggressive healing response than man, focal beta radiation attenuates wound healing and prolongs bleb survival. ${ }^{12,13}$ These studies demonstrated reduced fibroblast numbers, without excessive inflammation. Additionally, collagen deposition and bleb thickness tended to be reduced. Concerns that focal beta radiation treatment may actually induce rather than inhibit postoperative inflammation have not been borne out, however, either in animal models or in clinical practice. ${ }^{12,14}$

The first in vitro experimental data on beta radiation on ocular cells were published by Nevarez et al ${ }^{15}$ in 1987, who studied proliferation of cultured monkey fibroblasts following single doses of irradiation. Proliferation was reduced to $14 \%$ with doses of $1000 \mathrm{cGy}$ or more in this 
Table 1 Susceptibility of ocular structures to radiation damage

\begin{tabular}{|c|c|c|c|}
\hline Ocular tissue & Radiation dose & Latency & Effects \\
\hline \multirow[t]{5}{*}{ Conjunctiva } & 5000 cGy & 4-6 weeks & Conjunctivitis \\
\hline & $3000-5000$ cGy $y^{23,72,73}$ & 2-4 weeks & Late onset telangectatic vessels ( $27 \%$ of cases) ${ }^{72,73}$ \\
\hline & $>5000$ cGy & & Epithelial keratinisation $^{23}$ \\
\hline & & & Conjunctival cytological changes \\
\hline & 5000 cGy & 12 years & Symblepharon \\
\hline \multirow[t]{2}{*}{ Cornea } & $2000 \mathrm{cGy}^{23,74}$ & 4-6 weeks & Mild punctate keratitis ${ }^{23,74}$ \\
\hline & Higher doses ${ }^{73}$ & & Epithelial ulceration and stromal oedema ${ }^{73}$ \\
\hline \multirow[t]{2}{*}{ Sclera } & 750 cGy & $>10$ years & One isolated case of scleral thinning after treatment \\
\hline & 2400 cGy $^{35,36,75}$ & $3-20$ years & Scleral necrosis, infective scleritis ${ }^{35,36,75}$ \\
\hline \multirow[t]{2}{*}{ Uvea } & $1000-2000 c^{c G y}{ }^{76}$ & $3-4$ days & Mild transient uveitis $^{76}$ \\
\hline & $6000-8000$ cGy & $6-8$ weeks & Persistent, delayed onset uveitis \\
\hline \multirow[t]{2}{*}{ Lens } & 250 cGy & 6 months -20 years & Nonprogressive lens opacity \\
\hline & $750 \mathrm{cGy}^{21,22}$ & & Cataract $(50 \% \text { progressive })^{21,22}$ \\
\hline \multirow[t]{2}{*}{ Retina } & $1500 \mathrm{cGy}^{77}$ & $8-24$ days & Mild radiation retinopathy rarely reported (single report) ${ }^{77}$ \\
\hline & $3000 \mathrm{cGy}^{49}$ & $>6$ months & Higher risk of radiation retinopathy ${ }^{49}$ \\
\hline
\end{tabular}

aggressive model. Following this, in 1991 Khaw et al ${ }^{16}$ described the effects of beta radiation on in vitro cultures of human Tenon's fibroblasts, and similarly found a significant inhibition of fibroblast proliferation compared to control cells over a 14-day period. Constable et al ${ }^{17}$ examined the effect of beta radiation on human Tenons fibroblasts over a longer time period and examined the effect on cell cycling. They showed that dose-dependent inhibition of human Tenon's fibroblast proliferation up to a plateau at exposures of $1000 \mathrm{cGy}$ is due to cellular growth arrest rather than to cell killing. Cellular p53 levels were also measured. p53 is a neuropeptide that prevents cell replication in the presence of DNA damage, that is, it acts as a 'guardian of the genome'. Levels of p53 were found to be significantly increased over the 30-day study period, presumably in response to DNA damage caused by the radiation.

One important issue is how these cellular effects compare to those of 5-fluorouracil (5FU) and mitomycin $\mathrm{C}(\mathrm{MMC})$. Khaw et al showed that $5 \mathrm{FU}(25 \mathrm{mg} / \mathrm{ml})$ and MMC $(0.1 \mathrm{mg} / \mathrm{ml})$ both reduce fibroblast proliferation by at least $50 \%$ by inducing growth arrest in a manner similar to that following radiation. However, the effects of MMC do differ in an important way. Single applications of $0.4 \mathrm{mg} / \mathrm{ml} \mathrm{MMC}$ rapidly lead to high levels of cell death by apoptosis, an effect not seen after clinically relevant doses of radiation. ${ }^{18}$

\section{Suseptibility of ocular structures to radiation damage}

The safety of any therapeutic approach is of paramount importance and there are considerable data on the radiosensitivity of the ocular structures to ionising radiation. Chalupecky ${ }^{19}$ first studied the effects of radiation on the eye over 100 years ago. Current data on the susceptibility of ocular structures to radiation are summarised in Table 1.

\section{Radiation and the lens}

The lens has been recognised for many years to be the most radiosensitive structure in the eye. Many clinical and experimental studies have been published investigating the tolerance of the lens to radiation. ${ }^{20-22}$ Cataracts have not been reported with lens doses of radiation below $200 \mathrm{cGy}$, but nonprogressive lens changes have been sporadically recorded with doses just above this level. Merriam et al ${ }^{23}$ concluded that the minimum cataractogenic dose for a single treatment was 200 cGy to the lens epithelium, with the probability of cataract approaching unity for a dose of $750 \mathrm{cGy}$, although only $50 \%$ of these cases showed progressive change. The latent period for the onset of these lens opacities has been reported as varying between 6 months and 35 years, and appears to be inversely related to the total dose administered. Hilgers ${ }^{20}$ concluded that a surface dose (ie to the bare sclera) of 3000 cGy could be considered a safe noncataractogenic dose of ${ }^{90} \mathrm{Sr}$ beta radiation. Given the dose considerations above, the degree of penetration of beta radiation is crucial. Although the events leading to lens opacity are not fully understood, the germinative zone in the lens epithelium is considered to be the most important area. This part of the lens is relatively close to the limbus and may receive a particularly high proportion of radiation compared to the whole lens when beta radiation as applied to the anterior segment. Dose to the lens has been calculated assuming exponential decay of the surface dose. Using 
more sophisticated modelling, Gleckler et $a l^{24}$ estimated that the dose to the germinative epithelium is approximately $14 \%$ of the surface dose applied after pterygium surgery onto the bare sclera. The additional attenuation by the conjunctiva with a thickness of approximately $1 \mathrm{~mm}$ means that the lens dose following application after trabeculectomy is likely to be less than $10 \%{ }^{24}$

Attenuation is difficult to model through a structure such as conjunctiva (particularly, immediately after conjunctival surgery) because the presence of tissue, fluid, and air space causes interfaces which may have significant effects on transmission of beta radiation, that is, attenuating it further than through a homogenous medium. Individual variations in ocular anatomy, including anterior chamber depth, may also have an effect on the lens dose for a given surface dose.

In the use of trabeculectomy as a primary treatment for glaucoma in the developing world, the problem of subsequent development of lens opacity is particularly important. In a recent study from Tanzania, where trabeculectomy with mitomycin C was evaluated, $33 \%$ of patients developed significant cataract. This is clearly a major problem in such a setting where re-presentation for cataract extraction may not be feasible. There is some suggestion that trabeculectomy with mitomycin $\mathrm{C}$ and 5-fluorouracil may accentuate development of lens opacity more than trabeculectomy alone. The role of beta radiation in cataract progression after trabeculectomy is of great clinical importance. It is reassuring that beta radiation (750 cGy) has been used at Moorfields Eye Hospital on children and young adults for nearly 20 years and no patients have required cataract surgery. There is evidence that mitomycin $C$ does penetrate the sclera and has intraocular effects in man, but to what degree and how often this occurs is, in clinical practice, as yet unclear.

\section{Beta radiation in ophthalmology}

\section{Pterygium}

The most common use of beta radiation has been in the management of pterygium, with local application of a

${ }^{90} \mathrm{Sr}$ source to prevent recurrence. Iliff suggested that beta radiation may be particularly useful in ophthalmology in 1947, following from an earlier report by Burnam; however, its usefulness was limited by the need to use naturally occurring radon seeds. ${ }^{25-27}$ Friedell was the first to describe the clinical use of a ${ }^{90} \mathrm{Sr}$ source in 1950. It was suggested for a variety of uses including treatment of superficial tumours, vernal conjunctivitis, tuberculosis, and corneal vascularisation..$^{28}$ In the treatment of pterygium, initially a high dose of beta radiation was applied without surgical excision, the aim being to induce regression of the lesion. Administration after surgery, particularly for recurrent pterygia, was widely adopted, with subsequent reports indicating a low recurrence rate. Many reports were from Australia with a high prevalence and recurrence rate, presumably due to high levels of ultraviolet radiation. Doses administered varied considerably. Mead ${ }^{29}$ administered $2400 \mathrm{cGy}$ in a single dose. Other reports used doses from 1000 to 4000 cGy, often in divided fractions. ${ }^{30-33}$ Aswad and Baum $^{34}$ performed a trial that indicated that administration immediately after surgery was more effective than later administration. Typical doses have been of the order of 2000-6000 cGy, frequently given in fractions. A randomised controlled trial by de Kaiser demonstrated that beta radiation was effective in reducing the rate of recurrence. Beta radiation became widely used, particularly in Australia and the southern USA from the $1970 \mathrm{~s}$.

Adverse effects with beta radiation for pterygium have been widely reported. Earlier reports concentrated on lens opacity, conjunctival telangectasia, and other side effects of doses much higher than those used clinically after pterygium surgery. Cameron reported five subjects with varying degrees of scleral necrosis: he attributed these to poor surgical technique in four cases (excessive cautery) and overdosage (7200 cGy) in another.

Subsequently, Tarr and Constable reported a large series of eyes from western Australia. They reported 51 cases of scleral ulceration. The time lag between therapy and presentation was between 3 and 20 years, mean 12 years. They estimated a $2.6 \%$ rate of significant scleral necrosis in the long term after treatment. In all but one of the cases the patients had received at least $2400 \mathrm{cGy} .{ }^{35}$ One patient received $750 \mathrm{cGy}$ and developed a small $(1.5 \mathrm{~mm}$ diameter), punched-out ulcer covered with 'slightly' abnormal conjunctiva 10 years later. The other ulcers were larger, frequently very deep, with avascular conjunctival covering. Subsequent reports from the same centre reported on infective scleritis, with devastating ocular consequences, all patients having received over $2000 \mathrm{cGy} .{ }^{36}$ A subsequent report suggested that using lower doses was also associated with scleral infection. Mackenzie reported long-term follow-up (10 years) on 585 of an original 1102 patients in Queensland, Australia. Overall recurrence rate was $12 \%$. It was reported that $13 \%$ of eyes had some degree of scleral thinning and $4.5 \%$ had a significant degree of scleral thinning - defined as at least 50\% reduction in scleral thickness over an area at least $2 \mathrm{~mm}$ in diameter. The surgery was performed using a bare sclera technique and it is possible that this exacerbated the risk of late melting.

Use of beta radiation for pterygium has diminished, with conjunctival autografting and topical mitomycin C now being widely used. Currently, there is no conclusive 
evidence as to the optimum therapy conjunctival autografting is reasonably effective and appears to be safe; however, it is considerably more time consuming than other methods. ${ }^{37}$ Comparative data for beta radiation and mitomycin $\mathrm{C}$ are conflicting: a retrospective comparison from Japan suggested that mitomycin $\mathrm{C}$ was more effective; a study from Turkey suggested the converse, a Dutch study suggested equivalence; and a randomised controlled study from Australia suggested that beta radiation was more effective than either conjunctival autografting or mitomycin C. ${ }^{38-41}$ While initial reports indicated good safety with mitomycin $\mathrm{C}$, late complications of mitomycin $C$ use, including scleral necrosis and corneal perforation, have been reported that are remarkably similar to those of beta radiation. ${ }^{42-44}$

\section{Age-related macular degeneration}

In recent years, there has been persisting interest in the role of ionising radiation in the management of exudative ARMD following the first report by Chakravarthy et $a l^{45}$ using external beam therapy. Radiation has been shown to inhibit vascular endothelial cell proliferation and angiogenesis - both of which are key elements in the development of choroidal neovascularisation. ${ }^{46-48}$ The use of external beam treatment necessitates fractionation as individual doses of more than $500 \mathrm{cGy}$ or regimes with a total dose of more than $5000 \mathrm{cGy}$ result in unwanted side effects. ${ }^{23,49}$ However, the dose required to induce regression of vascular tissues in clinical practice is close to this level. ${ }^{50,51}$ Given these considerations, an alternative approach has been the use of an episcleral plaque placed close to the area of treatment.

Brachytherapy has utilised either palladium-103 ( $\left.{ }^{103} \mathrm{P}\right)$, a low-energy gamma emitter, or ${ }^{90} \mathrm{Sr}$. Studies have reported doses of between 500 and 2400 cGy to the target tissue. ${ }^{52,53}$ Dosimetric studies have demonstrated that a local approach leads to a considerably smaller radiation dose to the lens and optic nerve than for external beam therapy. When these doses are administered by an external beam, the dose given to the lens may be sufficient to induce cataract, as up to $50 \%$ of the maximum dose may fall on the posterior lens. The disadvantages include the need for incisional surgery. Whether these theoretical differences provide any practical advantage remains to be seen, however, external beam radiation has not been shown to be effective in trials reported so far. ${ }^{54-56}$

\section{Glaucoma drainage surgery}

The earliest publication specifically addressing the use of beta radiation with drainage surgery was by Iliff in 1944 .
In a review of surgical management of glaucoma in African-Americans, he reported an overall success rate of $40 \%$ in a historical control group, with eight of 11 cases receiving beta radiation having a successful outcome with at least 1-year follow-up. He reported that 'post operative beta radiation gave encouraging results, and was worthy of further trial' ${ }^{25}$ A further report by Cohen et $a l^{57}$ using a ${ }^{90} \mathrm{Sr}$ emitter showed success in eight of 10 patients. Cameron ${ }^{58}$ reported success in a small series from Australia on patients that had previously failed surgery. ${ }^{58}$ In 1991, Miller and Rice ${ }^{14}$ published the follow-up data in a series of 66 eyes with congenital glaucoma, 31 of which had been treated with 750 cGy beta radiation at the end of surgery. Analysis at 3 years showed that beta radiation was significantly protective against failure as compared to controls. O'Donoghue et al ${ }^{59}$ presented 1-year follow-up of a randomised controlled trial of beta radiation compared with postoperative 5fluorouracil. They concluded that the antiscarring effect of these two treatments was similar, but importantly that fewer of the irradiated eyes developed cystic blebs or corneal toxicity. ${ }^{59}$ In the same year, Lai and Ho presented their 1-year results in a prospective trial of the use of beta radiation combined with trabeculectomy compared to trabeculectomy alone in a cohort of uncomplicated cases of primary open-angle glaucoma in Hong Kong. Surgical failure was significantly reduced in the irradiated eyes $(9.52 \%)$ compared to the control eyes (26.09\%). ${ }^{60}$ Barnes et $a l^{61}$ recently reported on the use of beta radiation in white subjects with a low risk of failure. They did not see a significant difference in intraocular pressure or failure rate as there was a high success rate in both arms of the study and the study power was very limited. ${ }^{61}$

\section{Why beta radiation in glaucoma surgery}

The use of antiproliferatives has revolutionised glaucoma drainage surgery. ${ }^{62}$ However, the use of liquid antimetabolites may be associated with problems. The variability of the delivery of the drug between the impregnated sponge and the subconjunctival tissues means that accurate dosimetry has proven extremely difficult. ${ }^{63}$ They are used in liquid form, delivered by placing microsurgical sponges soaked in the drug directly onto the operative site. Furthermore, because they are liquids, they carry the risk of leakage away from the treatment site, leading to extraocular or, more seriously, intraocular toxicity. ${ }^{64,65}$ Both treatments have been associated with the development of extremely thin avascular filtration blebs, and these are associated with an increased risk of sight-threatening complications including profound hypotony and endophthalmitis. ${ }^{66-68}$

As previously illustrated, beta radiation has certain features that may make it suitable for use in glaucoma 
a

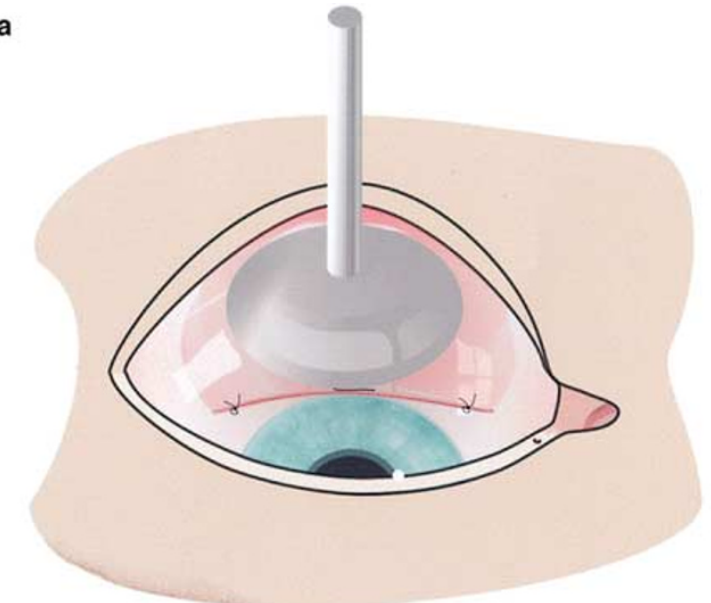

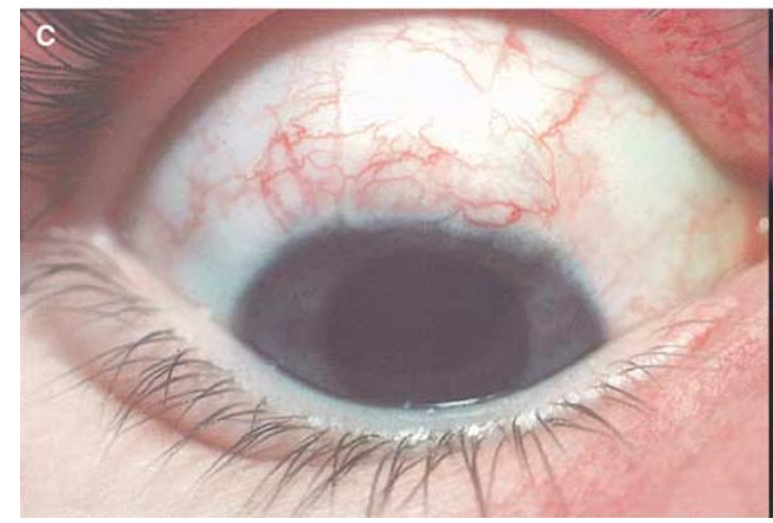

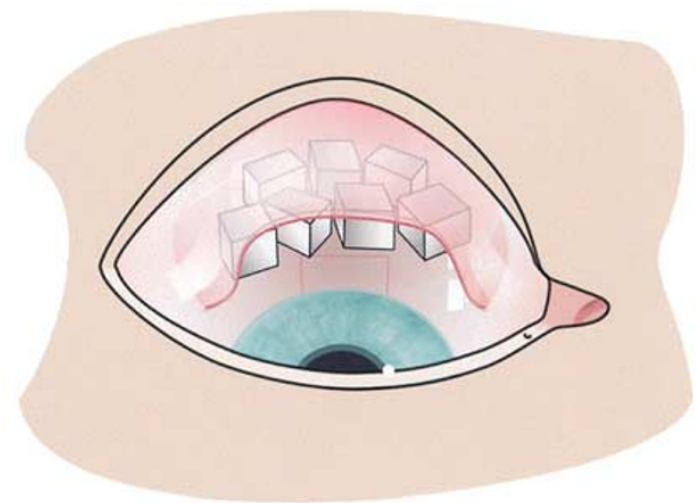

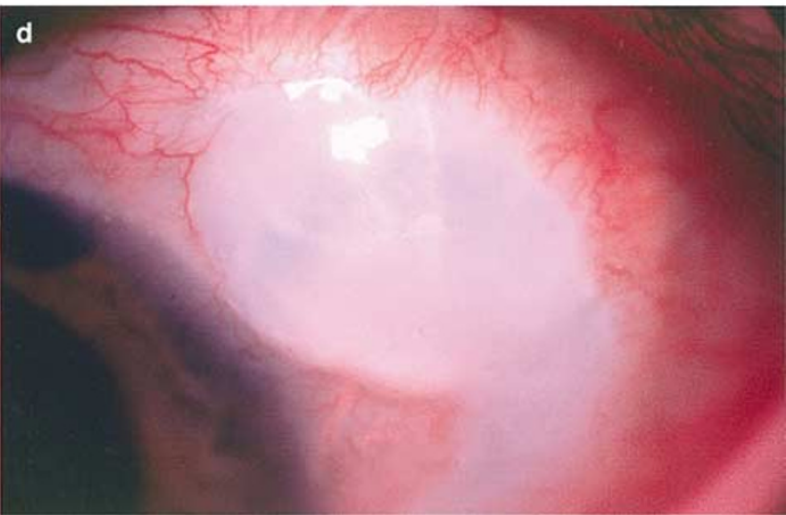

Figure 2 (a) Diagram illustrating placement of beta radiation at completion of surgery. (b) In contrast, extensive dissection required to apply antimetabolites to large area of sclera. (c) Bleb with diffuse morphology following application of beta radiation. (d) Focal, avascular bleb produced by focal application of MMC under a limbus based conjunctival flap.

surgery. Application of beta radiation is rapid and convenient, and the focal nature of application reduces the risk of accidental overdosage. Both dosimetry and the area treated can be controlled with accuracy. The size of the application area of antimetabolites has been shown to be important in the way that blebs develop, and large treatment areas seem to be more favourable. ${ }^{69}$ This is easy to control without extensive dissection if a customsized applicator is applied to the desired area, whereas more extensive dissection is required if a large treatment area is required with a liquid antimetabolite.

Additionally, there is no risk of leakage outside the treatment area, with which a liquid antimetabolite may lead to nonhealing of the wound edge. The actual nature of the bleb formed is different from that produced with MMC or 5FU, tending to be thicker and less avascular. This has been noted in clinical studies and also in animal models. ${ }^{59,70}$ Whether this is a result of treatment size effects or intrinsic differences between these modalities is unknown, but may be important in minimising the incidence of bleb complications including endophthalmitis (Figure 2).

For the developing world, there are additional practical advantages with beta radiation. The stability and long half-life of ${ }^{90} \mathrm{Sr}$ means that once obtained, an emitter can have a long working life (20 years plus), with only occasional recalibration. Sources are stable and easily stored, with no refrigeration required, and sustainability issues such as maintaining a good supply of drugs, and ongoing costs are not a problem. In the UK, capital outlay is currently significant (approximately UK $£ 5000$ ), but emitters could be made more cost-effectively. Clearly, the unit cost drops with increased turnover. Strict licensing laws may discourage use in many countries, as clinicians are required to obtain a special licence.

In comparison to its use for pterygium, beta radiation in glaucoma surgery may be safer for the following reasons. The dose of $1000 \mathrm{cGy}$ used is the optimum dose as determined in in vitro and in vivo studies. ${ }^{17}$ This is between 20 and $50 \%$ of the dose used for pterygium. 
Reports of scleral necrosis with this dose are extremely uncommon. The applicator is placed on the conjunctiva immediately following surgery rather than on bare sclera. This reduces the dose received by the sclera, as a significant proportion of the radiation is attenuated passing through the conjunctiva (approximately 30\% assuming a thickness of $1 \mathrm{~mm}$ ). Trabeculectomy is performed in the superior location, under the upper lid. The protection of the upper lid is important for providing protection to the bleb. It is known that interpalpebral blebs have a far greater incidence of bleb-related complications, particularly after antiscarring agents have been used. This is quite different from the situation following pterygium surgery where the bare sclera is interpalpebral and de-epithelialised. Both these factors may render the scleral tissue more susceptible to infection. Beta radiation has been used at Moorfields Eye Hospital for over 25 years in the management of paediatric glaucoma cases. During this time, the use of beta radiation has had an excellent safety profile, with no evidence of neoplastic effects or radiation-associated lens opacity.

\section{Summary}

Beta radiation is a practical method of applying radiation focally. In clinically used doses, it is effective in reducing the proliferative wound healing response, causing growth arrest without inhibiting other cellular functions. Its ocular safety profile is relatively well understood. Beta radiation has been in clinical use longer than most other methods of controlling scarring and was widely used for pterygium. Its use in that role has diminished with the uptake of other modalities, albeit without a strong supportive evidence base. Owing to its longevity, we are more aware of its long-term effects than is the case with other modalities. It may have clinical use in the management of ARMD and also for glaucoma surgery.

With the development of biotechnology-based approaches to the control of wound healing, it may be tempting to reject older and perhaps 'blunter' tools in our quest for better results. ${ }^{71}$ However, the applicability of these approaches to the bulk of the world's glaucoma population in the near future is questionable and it is appropriate to fully exploit our current approaches to controlling ocular wound healing. As the use of beta radiation may be especially suitable for use in the developing world, particularly in Africa, we are currently performing a randomised controlled trial of beta radiation in South Africa. Patients with primary glaucoma are randomised to standard trabeculectomy or trabeculectomy augmented with 1000 cGy of beta radiation immediately after surgery. We hope that this trial will help to improve treatment options in the management of this blinding condition.

\section{Acknowledgements}

Wellcome Trust 056045, MRC G9330070, and TFC Frost Foundation are acknowledged.

Proprietary interests: nil.

\section{References}

1 Casterella PJ, Teirstein PS. Prevention of coronary restenosis. Cardiol Rev 1999; 7: 219-231.

2 Raizner AE, Oesterle SN, Waksman R, Serruys PW, Colombo A, Lim YL et al. Inhibition of restenosis with beta-emitting radiotherapy: report of the Proliferation Reduction with Vascular Energy Trial (PREVENT). Circulation 2000; 102: 951-958.

3 Lommatzsch P. Treatment of choroidal melanomas with ${ }^{106} \mathrm{Ru} /{ }^{106} \mathrm{Rh}$ beta-ray applicators. Surv Ophthalmol 1974; 19: 85-100.

4 Lommatzsch PK, Werschnik C, Schuster E. Long-term follow-up of Ru-106/Rh-106 brachytherapy for posterior uveal melanoma. Graefes Arch Clin Exp Ophthalmol 2000; 238: 129-137.

5 Lommatzsch PK. Experiences in the treatment of malignant melanoma of the choroid with ${ }^{106} \mathrm{Ru}-{ }^{106} \mathrm{Rh}$ beta-ray applicators. Trans Ophthalmol Soc UK 1973; 93: 119-132.

6 Macintyre J. Radium and its therapeutic effects. BMJ 1903 2: 1526-1529.

7 Puck TT, Morkovin D, Marcus PI, Cieciura SJ. Action of X-rays on mammalian cells II: survival curves of cells from normal human tissues. J Exp Med 1957; 106: 485-500.

8 Desjardins A. The radiosensitiveness of cells and tissues and some medical implications. Science 1932; 75: 569-575.

9 Morrison DR, Kanai A, Gasset AR. Beta radiation inhibition of corneal healing. I. Tensile strength and ultrastructure change. Invest Ophthalmol 1971; 10: 826-839.

10 Meredith TA, Ficker L, Stevens R, Olkowski Z, Anderson M, Hartmann J et al. Suppression of experimental tractional retinal detachment by low-dose radiation therapy. Arch Ophthalmol 1988; 106: 673-675.

11 Binder S, Bonnet M, Velikay M, Gerard JP, Stolba U, Wedrich A et al. Radiation therapy in proliferative vitreoretinopathy. A prospective randomized study. Graefes Arch Clin Exp Ophthalmol 1994; 232: 211-214.

12 Friedman S, Soloman H, Dueker D. The effect of beta radiation on maintaining filtering blebs after glaucoma surgery in normal rabbits. Invest Ophthalmol Vis Sci (Suppl) 1987; 28: 272.

13 Friedman S, Dueker D, Soloman H, Wang R. The effect of beta radiation on normal rabbit conjunctiva and fibroblasts in culture. Invest Ophthalmol Vis Sci (Suppl) 1986; 27: 212.

14 Miller MH, Rice NS. Trabeculectomy combined with beta irradiation for congenital glaucoma. Br J Ophthalmol 1991; 75: 584-590.

15 Nevarez JA, Parrish RD, Heuer DK, Hajek AS, Houdek PV, Mallick KS. The effect of beta irradiation on monkey Tenon's capsule fibroblasts in tissue culture. Curr Eye Res 1987; 6: 719-723.

16 Khaw PT, Ward S, Grierson I, Rice NS. Effect of beta radiation on proliferating human Tenon's capsule fibroblasts. Br J Ophthalmol 1991; 75: 580-583.

17 Constable P, Occleston N, Cordeiro M, Kon C, Khaw PT. Long term growth arrest of human tenons fibroblasts 
following single doses of beta irradiation. $\mathrm{Br}$ J Ophthalmol 1998; 82: 448-452.

18 Occleston NL, Alexander RA, Mazure A, Larkin G, Khaw PT. Effects of single exposures to antiproliferative agents on ocular fibroblast-mediated collagen contraction. Invest Ophthalmol Vis Sci 1994; 35: 3681-3690.

19 Chalupecky H. Uber die wirkung der rontgenstralen auf dasauge und die haut. Zbl Augenheilk 1897; 21: 234-267.

20 Hilgers JHC. Strontium 90 B irradiation, cataractogenicity, and pterygium recurrence. Arch Ophthalmol 1966; 76: 329333.

21 von Sallmann L, Munoz CM, Drungis A. Effects of beta irradiation on the rabbit lens. Arch Ophthalmol 1953; 50: 727-736.

22 Thomas CI, Storaasli JP, Friedell HL. Lenticular changes associated with beta irradiation of the eye and their significance. Radiology 1962; 79: 588-597.

23 Merriam GR, Szechter A, Focht EF. The effects of ionizing radiations on the eye. Radiat Ther Oncol 1972; 6: 346-385.

24 Gleckler M, Valentine JD, Silberstein EB. Calculating lens dose and surface dose rates from ${ }^{90} \mathrm{Sr}$ ophthalmic applicators using Monte Carlo modeling. Med Phys 1998; 25: 29-36.

25 Iliff CE. Surgical control of glaucoma in the negro. Am J Ophthalmol 1944; 27: 731-738.

26 Iliff CE. Beta irradiation in ophthalmology. Arch Ophthalmol 1947; 38: 415-441.

27 Burnham CF, Neill $\mathrm{W}$. Use of beta ray radium applicator South Med J 1940; 33: 279-284.

28 Friedell HL, Thomas CI, Krohmer JS. Beta ray application to the eye with the description of an applicator utilizing strontium 90 and its clinical use. Am J Ophthalmol 1950; 33: $525-535$

29 Mead KW. Beta irradiation for recurrent pterygia. Trans Ophthalmol Soc Aust 1956; 16: 101-109.

30 MacKenzie FD, Hirst LW, Kynaston B, Bain C. Recurrence rate and complications after beta irradiation for pterygia. Ophthalmology 1991; 98: 1776-1780; discussion 1781.

31 The Fluorouracil Filtering Surgery Study Group. Five-year follow-up of the fluorouracil filtering surgery study. Am J Ophthalmol 1996; 121: 349-366.

32 Herbstein AU, Donovan JK. Pterygium removal. A technique to prevent recurrence. $\mathrm{Br}$ J Ophthalmol 1968; 52: $162-165$

33 Paryani SB, Scott WP, Wells Jr JW, Johnson DW, Chobe RJ, Kuruvilla A et al. Management of pterygium with surgery and radiation therapy. The North Florida Pterygium Study Group. Int J Radiat Oncol Biol Phys 1994; 28: 101-103.

34 Aswad MI, Baum J. Optimal time for postoperative irradiation of pterygia. Ophthalmology 1987; 94(11): 1450-1451.

35 Tarr KH, Constable IJ. Late complications of pterygium treatment. Br J Ophthalmol 1980; 64: 496-505.

36 Moriarty AP, Crawford GJ, McAllister IL, Constable IJ. Severe corneoscleral infection. A complication of beta irradiation scleral necrosis following pterygium excision. Arch Ophthalmol 1993; 111: 947-951.

37 Sanchez-Thorin JC, Rocha G, Yelin JB. Meta-analysis on the recurrence rates after bare sclera resection with and without mitomycin $\mathrm{C}$ use and conjunctival autograft placement in surgery for primary pterygium. Br J Ophthalmol 1998; 82: 661-665.

38 de Keizer RJ. Pterygium excision with free conjunctival autograft (FCG) versus postoperative strontium $90\left({ }^{90} \mathrm{Sr}\right)$ beta-irradiation. A prospective study. Int Ophthalmol 1997; 21: 335-341.

39 Amano S, Motoyama Y, Oshika T, Eguchi S, Eguchi K. Comparative study of intraoperative mitomycin $\mathrm{C}$ and beta irradiation in pterygium surgery. Br J Ophthalmol 2000; 84: 618-621.

40 Snibson GR, Luu CD, McKenzie JD, Taylor HR. A prospective randomised controlled trial of beta radiation, mitomycin C, and conjunctival transplantation in the surgical management of pterygium. Invest Ophthalmol Vis Sci 1996; 37: s703.

41 Simsek T, Gunalp I, Atilla H. Comparative efficacy of betairradiation and mitomycin-C in primary and recurrent pterygium. Eur J Ophthalmol 2001; 11: 126-132.

42 Rubinfeld RS, Pfister RR, Stein RM, Foster CS, Martin NF, Stoleru $\mathrm{S}$ et al. Serious complications of topical mitomycin-C after pterygium surgery. Ophthalmology 1992; 99: 1647-1654.

43 Kassir MS. [Corneal perforation after excision of pterygium and use of $0.02 \%$ mitomycin eyedrops]. J Fr Ophtalmol 1999; 22: 776-779.

44 Hayasaka S, Iwasa Y, Nagaki Y, Kadoi C, Matsumoto M, Hayasaka $\mathrm{Y}$. Late complications after pterygium excision with high dose mitomycin C instillation. $\mathrm{Br} J$ Ophthalmol 2000; 84: 1081-1082.

45 Chakravarthy U, Houston RF, Archer DB. Treatment of agerelated subfoveal neovascular membranes by teletherapy: a pilot study. Br J Ophthalmol 1993; 77: 265-273.

46 Reinhold HS, Buisman GH. Radiosensitivity of capillary endothelium. Br J Radiol 1973; 46: 54-57.

47 Arlett CF, Harcourt SA. Survey of radiosensitivity in a variety of human cell strains. Cancer Res 1980; 40: 926-932.

48 Grossniklaus HE, Martinez JA, Brown VB, Lambert HM, Sternberg Jr P, Capone Jr A et al. Immunohistochemical and histochemical properties of surgically excised subretinal neovascular membranes in age-related macular degeneration. Am J Ophthalmol 1992; 114: 464-472.

49 Brown GC, Shields JA, Sanborn G, Augsburger JJ, Savino PJ, Schatz NJ. Radiation retinopathy. Ophthalmology 1982; 89: 1494-1501.

50 Steiner L, Lindquist C, Adler JR, Torner JC, Alves W, Steiner $\mathrm{M}$. Clinical outcome of radiosurgery for cerebral arteriovenous malformations. J Neurosurg 1992; 77: 1-8.

51 Lunsford LD, Kondziolka D, Flickinger JC, Bissonette DJ, Jungreis CA, Maitz AH et al. Stereotactic radiosurgery for arteriovenous malformations of the brain. J Neurosurg 1991; 75: 512-524.

52 Finger PT, Berson A, Ng T, Szechter A. Ophthalmic plaque radiotherapy for age-related macular degeneration associated with subretinal neovascularization. Am J Ophthalmol 1999; 127: 170-177.

53 Jaakkola A, Heikkonen J, Tommila P, Laatikainen L, Immonen I. Strontium plaque irradiation of subfoveal neovascular membranes in age-related macular degeneration. Graefes Arch Clin Exp Ophthalmol 1998; 236: 24-30.

54 Radiation Therapy for Age-related Macular Degeneration. A prospective, randomized, double-masked trial on radiation therapy for neovascular age-related macular degeneration (RAD Study). Ophthalmology 1999; 106: 2239-2247.

55 Bergink GJ, Hoyng CB, van der Maazen RW, Vingerling JR, van Daal WA, Deutman AF. A randomized controlled clinical trial on the efficacy of radiation therapy in the control of subfoveal choroidal neovascularization in age- 
related macular degeneration: radiation versus observation. Graefes Arch Clin Exp Ophthalmol 1998; 236: 321-325.

56 Char DH, Irvine AI, Posner MD, Quivey J, Phillips TL, Kroll S. Randomized trial of radiation for age-related macular degeneration. Am J Ophthalmol 1999; 127: 574-578.

57 Cohen LB, Graham MD, Fry WE. Beta radiation as an adjunct to glaucoma surgery in the negro. Am J Ophthalmol 1959; 47: 53-60.

58 Cameron ME. Beta irradiation as an adjunct to surgery in refractory glaucoma. Trans Aust Coll Ophthalmol 1970; 2: 53-60.

59 O'Donoghue H, Sanders D, Ayliffe W, Ridgway A. Strontium 90 vs 5-FU as adjunct to surgery for patients at high risk of trabeculectomy failure: a prospective randomised trial. Invest Ophthalmol Vis Sci 1994; 35: 1432 (abstract).

60 Lai J, Ho C. Trabeculectomy combined with beta irradiation in uncomplicated primary open angle glaucoma. Invest Ophthalmol Vis Sci 1994; 34: 1432 (Absract).

61 Barnes RM, Mora JS, Best SJ. Beta radiation as an adjunct to low-risk trabeculectomy. Clin Exp Ophthalmol 2000; 28: 259-262.

62 Chen PP, Yamamoto T, Sawada A, Parrish RK, 2nd,Kitazawa Y. Use of antifibrosis agents and glaucoma drainage devices in the American and Japanese Glaucoma Societies. J Glaucoma 1997; 6: 192-196.

63 Wilkins MR, Occleston NL, Kotecha A, Waters L, Khaw PT. Sponge delivery variables and tissue levels of 5-fluorouracil. Br J Ophthalmol 2000; 84: 92-97.

64 Khaw PT. Antiproliferative agents and the prevention of scarring after surgery: friend or foe? Br J Ophthalmol 1995; 79: 627.

65 Franks W, Hitchings R. Complications of 5-fluorouracil after trabeculectomy. Eye 1991; 5: 385-389.

66 Shields MB, Scroggs MW, Sloop CM, Simmons RB. Clinical and histopathologic observations concerning hypotony after trabeculectomy with adjunctive mitomycin C. Am J Ophthalmol 1993; 116: 673-683.

67 Zacharia PT, Deppermann SR, Schuman JS. Ocular hypotony after trabeculectomy with mitomycin C. Am J Ophthalmol 1993; 116: 314-326.

68 Wolner B, Liebmann JM, Sassani JW, Ritch R, Speaker M, Marmor M. Late bleb-related endophthalmitis after trabeculectomy with adjunctive 5-fluorouracil. Ophthalmology 1991; 98: 1053-1060.

69 Cordeiro MF, Constable PH, Alexander RA, Bhattacharya SS, Khaw PT. Effect of varying the mitomycin-C treatment area in glaucoma filtration surgery in the rabbit. Invest Ophthalmol Vis Sci 1997; 38: 1639-1646.

70 Constable $\mathrm{PH}$. The effect of single doses of beta radiation on the wound healing functions of ocular fibroblasts. MD thesis, University of Cambridge, 1999.

71 Cordeiro MF, Gay JA, Khaw PT. Human anti-transforming growth factor-beta2 antibody: a new glaucoma anti-scarring agent. Invest Ophthalmol Vis Sci 1999; 40: 2225-2234.

72 Tong EC, Zaret MM, Rubenfeld S. Cellular changes in the conjunctiva after strontium 90 treatment for pterygium. Am J Roentgenol Radium Ther Nucl Med 1969; 106: 848-853.

73 Barron A, McDonald JE, Hughes WF. Long-term complications of beta-radiation therapy in ophthalmology. Trans Am Ophthalmol Soc 1970; 68: 112-128.

74 Mann WA, Watt RH. Late corneal changes following X-ray therapy. Am J Ophthalmol 1958; 45: 137

75 Moriarty AP, Crawford GJ, McAllister IL, Constable IJ. Fungal corneoscleritis complicating beta-irradiationinduced scleral necrosis following pterygium excision. Eye 1993; 7: 525-528.

76 Lederman M. Radiotherapy of diseases of cornea. J Fac Radiol 1952; 4: 97.

77 Perrers-Taylor M, Brinkley D, Reynolds T. Choroido-retinal damage as a complication of radiotherapy. Acta Radiol Ther Phys Biol 1965; 3: 431-440. 